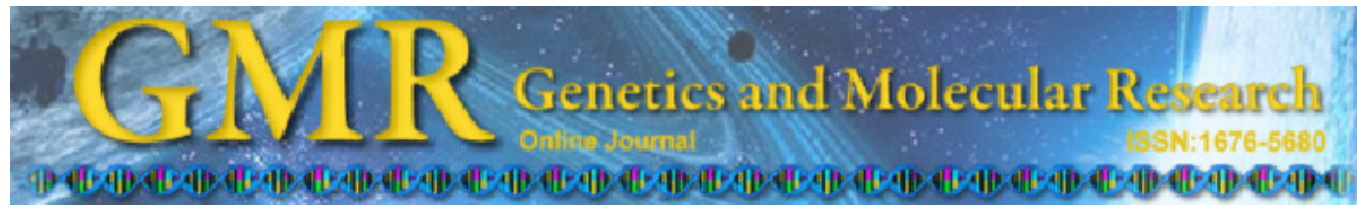

\title{
Effects of the antipsoriatic drug dithranol on E2A and caspase-9 gene expression in vitro
}

\author{
C. Ronpirin ${ }^{1}$ and T. Tencomnao ${ }^{2}$ \\ ${ }^{1}$ Department of Preclinical Science, Faculty of Medicine, \\ Thammasat University, Pathumthani, Thailand \\ Chulalongkorn University, Bangkok, Thailand \\ Corresponding author: C. Ronpirin \\ E-mail: cronpirin@yahoo.com \\ Genet. Mol. Res. 11 (1): 412-420 (2012) \\ Received March 29, 2011 \\ Accepted December 3, 2011 \\ Published February 17, 2012 \\ DOI http://dx.doi.org/10.4238/2012.February.17.3
}

${ }^{2}$ Department of Clinical Chemistry, Faculty of Allied Health Sciences, Center for Excellence in Omics-Nano Medical Technology Development Project,

ABSTRACT. Although the precise causes of psoriasis remain to be elucidated, psoriasis has been known as a disorder in which factors in the immune system, enzymes and other biochemical substances that regulate skin cell division are functionally imbalanced, thereby resulting in rapid proliferation of keratinocytes and incomplete keratinization. The expression of candidate genes such as E2A and caspase-9, which have been recognized to play a critical role in cellular proliferation/ differentiation and apoptosis, is of great interest. They may be therapeutically targeted by the antipsoriatic drug, dithranol. We examined the molecular effects of dithranol on the mRNA and protein expression levels of E2A and caspase-9 in the HaCaT keratinocyte cell line. The $\mathrm{HaCaT}$ cells were treated with $0-0.5 \mu \mathrm{g} / \mathrm{mL}$ dithranol for $30 \mathrm{~min}$. After dithranol was washed out, the HaCaT cells were cultured for $2 \mathrm{~h}$, and their total cellular RNA and proteins were isolated. Quantitative realtime reverse transcriptase-polymerase chain reaction and Western blot were performed to determine the mRNA and protein levels of these two genes. We found that dithranol treatment in the range of $0.25-0.5 \mu \mathrm{g} /$ $\mathrm{mL}$ slightly upregulated the mRNA expression of E2A and caspase- 9 approximately 1.5 - and 1.2-fold, respectively. However, undetectable 
change and minor downregulation of the protein expression levels were observed for E2A and caspase-9, respectively. Consequently, these genes appear not to be viable therapeutic targets for dithranol.

Key words: Psoriasis; Dithranol; E2A; Caspase-9; Gene expression; Human keratinocytes

\section{INTRODUCTION}

Psoriasis is a common, chronic skin disease, affecting approximately $2-4 \%$ of the population worldwide. It is characterized by immune activation, increased proliferation and abnormal differentiation of keratinocytes. The disease is of great concern due to its incurable nature (Schon and Boehncke, 2005; Lowes et al., 2007). Dithranol (1,8-dihydroxy-9-anthrone), also referred to as anthralin, is one of the crucial topical antipsoriatic drugs (Kemeny et al., 1990; Pavithran, 2001). It is a very effective compound in the treatment of active psoriasis, but its molecular mechanism of action is still not well understood.

Since the mechanism or disease process to explain psoriasis has not yet been fully elucidated, an investigation on the roles of numerous candidate genes as molecular biomarkers responsible for the pathogenesis of psoriasis is undergoing. The helix-loop-helix transcription factor Id1 (inhibitor of differentiation or inhibitor of DNA binding), known to function in suppressing cell differentiation and promoting cell proliferation, has recently received much attention regarding psoriasis. In particular, increased Id 1 gene expression was revealed in keratinocytes of psoriatic patients' skin (Bjorntorp et al., 2003), and an activated Id1 pathway was subsequently corroborated by another study (Mark et al., 2006). In a cellular model of psoriasis such as the HaCaT keratinocyte cell line, the Id1 mRNA was shown to be highly expressed (Langlands et al., 2000). Recently, the molecular role of Id1 was further highlighted in psoriasis since we found that the levels of Id1 transcripts in peripheral blood mononuclear cells of psoriatic patients were approximately 2 -fold higher than those in controls (Ronpirin et al., 2010). Of particular interest, the cellular function of the Id1 protein is regulated via binding with other interactors such as E2A proteins (Yan et al., 1997; Engel and Murre, 2001; Perk et al., 2005; Kee, 2009). Specifically, E2A can form homodimers and heterodimers due to its interaction with E2A and Id1, respectively. If E2A/Id1 heterodimers occur in cells, the protein complex is unable to bind to a corresponding gene promoter, thus leading to prohibition and promotion of cell differentiation and proliferation, respectively. By contrast, E2A/E2A homodimers binding to a gene promoter result in a cell differentiation. Therefore, the balance between Id1 and E2A proteins is extremely critical for eukaryotic cells (Olson and Klein, 1994). Nevertheless, the effect of dithranol on E2A gene expression has never previously been elucidated in $\mathrm{HaCaT}$ cells.

Hyperproliferative keratinocytes in psoriasis may also be likely due to dysregulated apoptosis since apoptosis is a physiological mechanism of homeostasis and development. In this regard, caspases are the executioners of apoptosis, and caspase-9 is particularly responsible for initiating the caspase activation cascade during apoptosis (Kuida, 2000). Interestingly, caspase-9 was shown to be reduced in psoriatic epidermis (Oztas et al., 2006). An in vivo study showed improvement of the psoriatic skin following effective dithranol therapy, and molecular alterations in apoptotic biomarkers including Bcl-2, Bcl-x, Bax, Fas, and Fas ligand were observed (Yamamoto and Nishioka, 2003). Nonetheless, the effect of dithranol on caspase-9 gene expression has to date not been fully understood. 
The objective of this study was to investigate the molecular effect of dithranol on the mRNA and protein expression levels of both E2A and caspase-9 in the HaCaT keratinocyte cell line. $\mathrm{HaCaT}$ cells were established as the first permanent epithelial cell line from adult human skin, and have been proven to exhibit normal differentiation. Therefore, this particular cell line could be considered a promising tool for studying the regulation of keratinization in human cells (Boukamp et al., 1988). The HaCaT cell line was chosen for this study since it has been demonstrated to be a suitable cellular model of psoriasis according to previous reports (Farkas et al., 2001; Tencomnao et al., 2009).

\section{MATERIAL AND METHODS}

\section{Cell culture}

The human keratinocyte cell line, HaCaT, was purchased from (CLS-Cell Lines Service, Eppelheim, Germany) (Boukamp et al., 1988). The cells were cultured in Dulbecco's modified Eagle's medium (DMEM; HyClone, Logan, UT, USA) supplemented with 10\% fetal bovine serum (FBS; HyClone), and cells were maintained at $37^{\circ} \mathrm{C}$ in a humidified atmosphere at $5 \% \mathrm{CO}_{2}$.

\section{Dithranol treatment}

Dithranol treatment was performed following a procedure previously described by Farkas et al. (2001) with minor modifications (Tencomnao et al., 2009). In brief, cultured $\mathrm{HaCaT}$ cells at about $90 \%$ confluence in a $60-\mathrm{mm}$ plate were washed with phosphate buffered saline (PBS) under sterile conditions and were incubated for $30 \mathrm{~min}$ at $37^{\circ} \mathrm{C}$ in a humidified atmosphere at $5 \% \mathrm{CO}_{2}$ with increasing concentrations of dithranol $(0.1,0.25$ and $0.5 \mu \mathrm{g} / \mathrm{mL})$ (Sigma, St. Louis, MO, USA) in DMEM containing 0.5\% FBS. Dithranol was always freshly dissolved in acetone and used immediately. Control cells were treated with the acetone only or left untreated. After dithranol treatment, treated cells were washed with PBS and were cultured in DMEM containing $10 \%$ FBS for $2 \mathrm{~h}$ at $37^{\circ} \mathrm{C}$ in a humidified atmosphere at $5 \% \mathrm{CO}_{2}$ prior to isolations of total cellular RNA and proteins for subsequent experiments.

\section{Total RNA extraction and cDNA synthesis}

Total cellular RNA isolation was carried out using Trizol reagent (Invitrogen, Carlsbad, CA, USA) according to manufacturer instructions. The amount of RNA was determined by absorbance at $260 \mathrm{~nm}$. Prior to real-time reverse transcriptase-polymerase chain reaction (RT-PCR), about $1 \mu \mathrm{g}$ of the total RNA was treated with $10^{-5} \mathrm{U}$ deoxyribonuclease I (DNase I; Invitrogen) for $15 \mathrm{~min}$ at $25^{\circ} \mathrm{C}$. First-strand cDNA was synthesized from about $250 \mathrm{ng}$ DNase I-treated RNA for each sample using ImProm-II ${ }^{\mathrm{TM}}$ Reverse Transcription System (Promega, Madison, WI, USA) with oligo(dT) ${ }_{17}$ primer following the manufacturer protocol. Reverse transcription was carried out at $50^{\circ} \mathrm{C}$ for $60 \mathrm{~min}$.

\section{Quantitative real-time PCR}

After cDNA synthesis, real-time PCR was performed on the StepOnePlus ${ }^{\mathrm{TM}}$ (Applied 
Biosystems, Foster City, CA, USA) using TaqMan ${ }^{\circledR}$ Universal PCR Master Mix and TaqMan ${ }^{\circledR}$ Gene Expression Assays probe and primer mix (Applied Biosystems), according to manufacturer instructions. The assay identification numbers of E2A, caspase-9 and ubiquitin C (UBC) were Hs00413032_ml, Hs00154261_ml and Hs00824723_ml, respectively. All gene-specific probes were labeled using a reporter dye FAM at the 5 '-end and a non-fluorescent quencher at the $3^{\prime}$-end of probe. The thermal cycler conditions were as follows: hold for $10 \mathrm{~min}$ at $95^{\circ} \mathrm{C}$ followed by two-step PCR for 40 cycles of $95^{\circ} \mathrm{C}$ for $15 \mathrm{~s}$ followed by $60^{\circ} \mathrm{C}$ for $1 \mathrm{~min}$. Amplification reactions in triplicate for each sample were performed and the results were normalized to the UBC gene expression level. An analysis of relative gene expression data was performed using the Applied Biosystems StepOne ${ }^{\mathrm{TM}}$ Real-time PCR Software v 2.0 with regard to the fold change in studied gene expression normalized to endogenous control. The data for each dithranol concentration treatment represented fold change in normalized mRNA expression relative to that at $0 \mu \mathrm{g} / \mathrm{mL}$ dithranol. The relative expression in fold change was arbitrarily set at 1 .

\section{Total protein isolation and quantification}

Total protein isolation from the $\mathrm{HaCaT}$ cells was performed using Nonidet-P40 (NP40) lysis buffer (1\% NP-40, $20 \mathrm{mM}$ Tris, $\mathrm{pH} 7.4,150 \mathrm{mM} \mathrm{NaCl}, 3 \%$ glycerol, $1.5 \mathrm{mM}$ EDTA) containing protease inhibitors. Protein concentrations were determined according to the Bradford method (Bradford, 1976) using a protein assay kit (Bio-Rad, Hercules, CA, USA) and bovine serum albumin (BSA; Sigma) as a standard.

\section{Western blot analysis}

Briefly, $15 \mu \mathrm{g}$ extracts was fractionated by $10 \%$ SDS-polyacrylamide electrophoresis and electrotransferred onto a nitrocellulose membrane. The membrane was incubated in blocking solution (5\% nonfat dry milk, $0.1 \%$ Tween 20 in PBS or 3\% BSA, $0.5 \%$ Tween 20 in PBS) for $1 \mathrm{~h}$ at room temperature. The blot was washed twice for 15 min each in PBS-Tween $20(0.1 \%)$, then incubated for $1 \mathrm{~h}$ at room temperature with primary antibody solution. The primary antibody solution used for each protein was either a 1:2000 dilution of polyclonal rabbit anti-E2A (cat. No. sc-349; Santa Cruz Biotechnology, Santa Cruz, CA, USA), a 1:5000 dilution of polyclonal rabbit anti-caspase-9 (cat. No. 9502; Cell Signaling Technology, Beverly, MA, USA) or a 1:4000 dilution of polyclonal rabbit glyceraldehyde 3-phosphate dehydrogenase (GAPDH; cat. No. sc-25778; Santa Cruz Biotechnology). The blot was washed twice for 15 min each in PBS-Tween $20(0.1 \%)$, then incubated for $1 \mathrm{~h}$ at room temperature with a 1:5000 dilution of an affinity purified goat anti-rabbit IgG coupled to horseradish peroxidase (cat. No. 7074; Cell Signaling Technology). After washing, the immunoreactive protein bands were detected using LumiGLO reagent and peroxide (Cell Signaling) for E2A (75 kDa) and GAPDH (37 kDa), while using SuperSignal West Femto Maximum Sensitivity Substrate (Pierce, Arlington Heights, IL, USA) for full-length caspase-9 or procaspase-9 (47 kDa) and its active form or caspase-9 $(37 \mathrm{kDa})$.

\section{Statistical analysis}

Each experiment was performed in triplicate, and data were reported as fold over 
$0 \mu \mathrm{g} / \mathrm{mL}$ dithranol concentration for both quantitative real-time PCR and Western blot. Regarding the Western blot experiments, all band densities were analyzed by 1-D Multi Lane Densitometry program in an AlphaImager 2000 (Alpha Innotech Corp., San Leandro, CA, USA). Protein band densities from each dithranol concentration were normalized to GAPDH densities. Data are reported as means \pm SD for three independent experiments and were analyzed by the Student $t$-test. Differences at $\mathrm{P}<0.05$ were considered to be significant.

\section{RESULTS}

\section{Quantitative real-time RT-PCR}

In the current study, we assessed the effect of dithranol on mRNA expression of E2A and caspase-9 using quantitative PCR approach. A housekeeping gene UBC was used as an internal control. After $2 \mathrm{~h}$ of dithranol treatment, our result showed that normalized E2A mRNA transcripts of HaCaT cells were increased as dithranol concentrations used were increasing (Figure 1). As compared to $0 \mu \mathrm{g} / \mathrm{mL}$ dithranol concentration (acetone-treated cells), the expression of E2A mRNA transcripts was increased by about 1.5 -fold that was considered to be statistically significant $(\mathrm{P}<0.05)$ when $0.5 \mu \mathrm{g} / \mathrm{mL}$ dithranol was used for the treatment. Although no statistical significance was reached when treating $\mathrm{HaCaT}$ cells with $0.25 \mu \mathrm{g} / \mathrm{mL}$ dithranol, a tendency of E2A upregulation was observed. With regard to the normalized caspase- 9 transcripts, they were significantly increased $(\mathrm{P}<0.05)$ by approximately 1.2 -fold over that of $0 \mu \mathrm{g} / \mathrm{mL}$ dithranol treatment when concentration of either 0.25 or $0.5 \mu \mathrm{g} / \mathrm{mL}$ dithranol was applied to the HaCaT cells (Figure 2). At $0.1 \mu \mathrm{g} / \mathrm{mL}$ dithranol treatment, almost significant upregulation of the caspase-9 mRNA transcripts was observed. Taken together, the upregulation effect of dithranol was concentration-dependent for both E2A and caspase-9 mRNA transcripts in the $\mathrm{HaCaT}$ cells although slight changes in mRNA expression levels were experimentally evident.

\section{Western blot analysis}

We further evaluated the expression of both genes in protein levels using Western blot analysis. Total protein was isolated from the HaCaT cells after $2 \mathrm{~h}$ of dithanol treatment. A housekeeping gene GAPDH was used as an internal control. No significant difference in the expression of the E2A protein was detected although various concentrations of dithranol were applied (Figure 3). By contrast, tendency towards downregulation of caspase- 9 was observed when increasing the concentrations of dithranol, and the $\mathrm{HaCaT}$ cells treated with $0.5 \mu \mathrm{g} / \mathrm{mL}$ dithranol had the normalized protein levels of fulllength caspase-9 (procaspase-9) and its active form (caspase-9) significantly decreased $(\mathrm{P}<0.05)$ to approximately 0.7 - and 0.6 -fold over that of $0 \mu \mathrm{g} / \mathrm{mL}$ dithranol treatment, respectively (Figure 4). Therefore, the expression level of the E2A protein remained unchanged in the $\mathrm{HaCaT}$ cells treated with increasing dithranol concentrations, while slight downregulation of both forms of caspase- 9 at $0.5 \mu \mathrm{g} / \mathrm{mL}$ dithranol treatment was observed. 


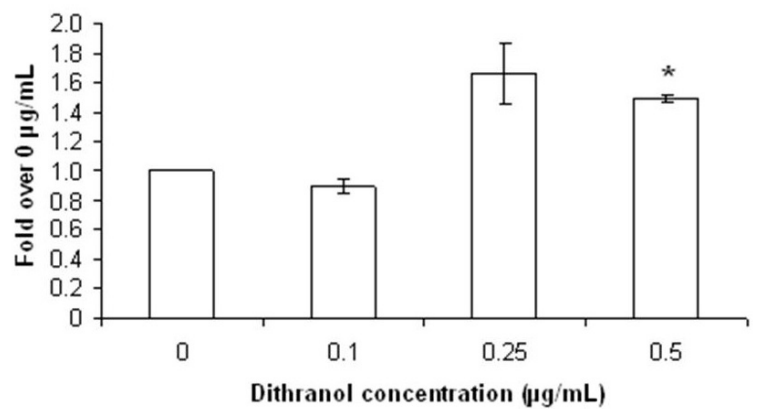

Figure 1. Quantitative real-time RT-PCR analysis of E2A expression in HaCaT cells treated with increasing dithranol concentrations $(0,0.1,0.25$, and $0.5 \mu \mathrm{g} / \mathrm{mL})$ for $2 \mathrm{~h}$. Average fold over expression at $0 \mu \mathrm{g} / \mathrm{mL}$ dithranol. $* \mathrm{P}<0.05$ indicating a statistically significant difference.

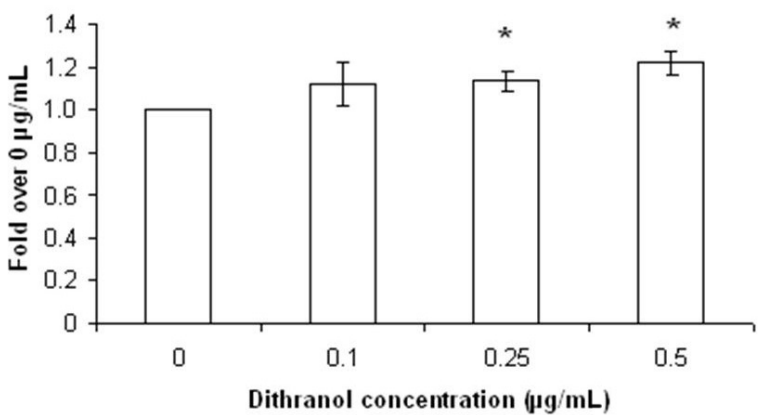

Figure 2. Quantitative real-time RT-PCR analysis of caspase-9 expression in HaCaT cells treated with increasing dithranol concentrations $(0,0.1,0.25$, and $0.5 \mu \mathrm{g} / \mathrm{mL})$ for $2 \mathrm{~h}$. Average fold over expression at $0 \mu \mathrm{g} / \mathrm{mL}$ dithranol. $* \mathrm{P}<0.05$ indicating a statistically significant difference.

A

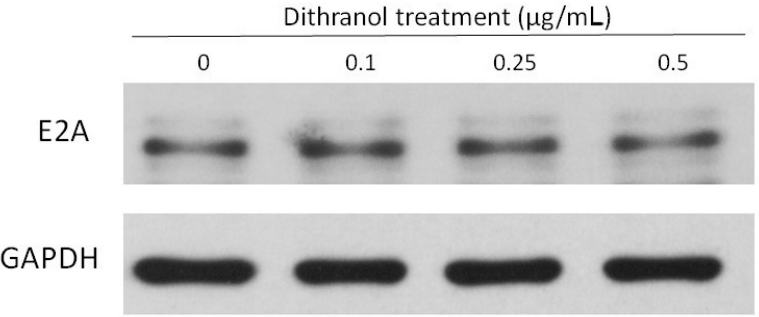

B

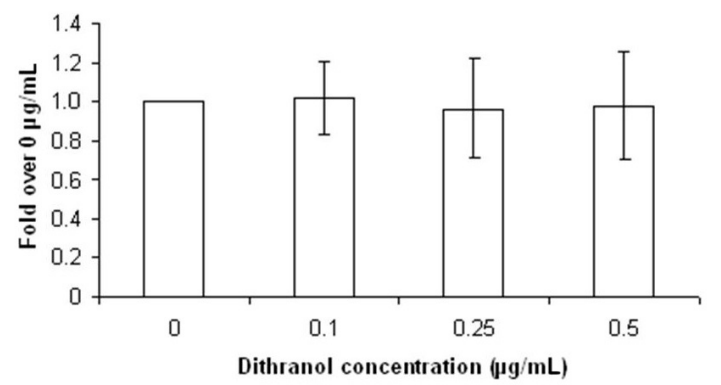

Figure 3. Western blot analysis of E2A in $\mathrm{HaCaT}$ cells treated with increasing dithranol concentrations $(0,0.1,0.25$, and $0.5 \mu \mathrm{g} / \mathrm{mL}$ ) for $2 \mathrm{~h}$. A. Immunodetected protein band for E2A and GAPDH. B. Average fold over expression at $0 \mu \mathrm{g} / \mathrm{mL}$ dithranol for the E2A protein. 
A

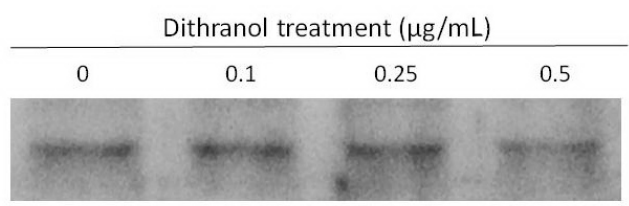

Caspase-9

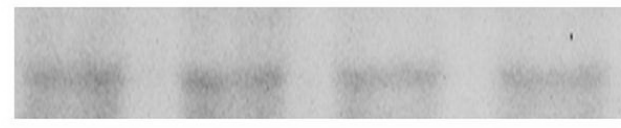

GAPDH

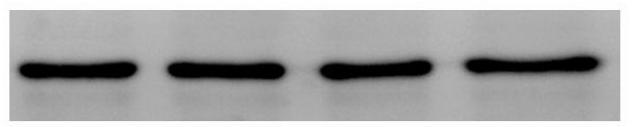

B

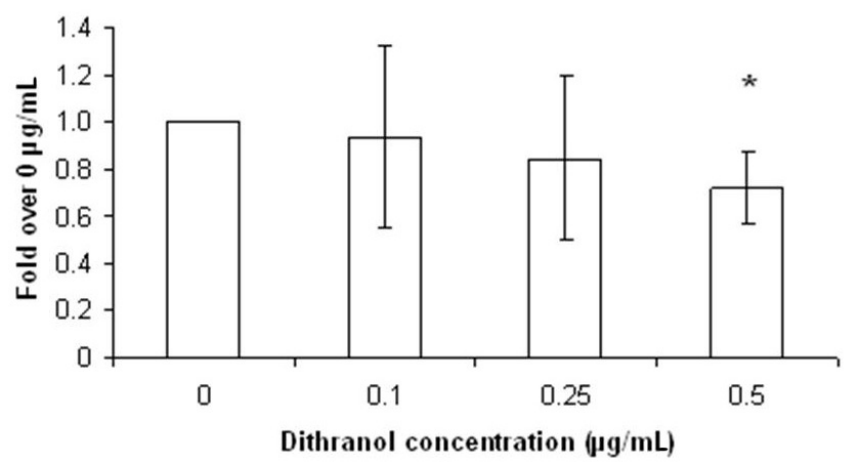

C

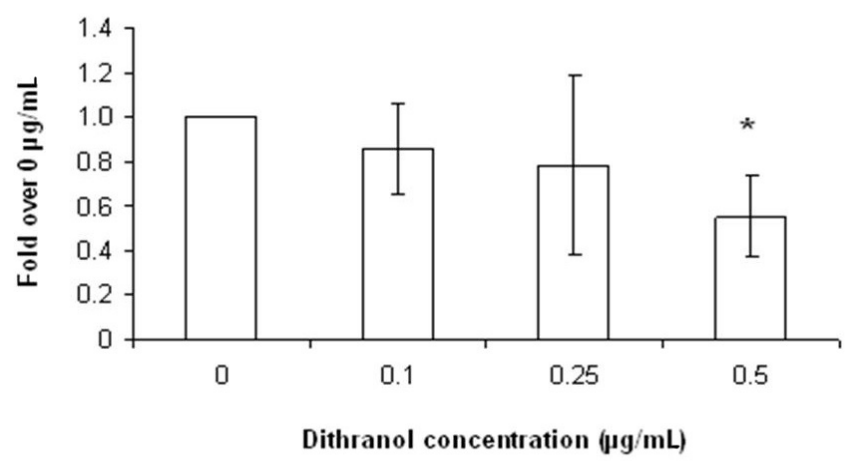

Figure 4. Western blot analysis of caspase- 9 in $\mathrm{HaCaT}$ cells treated with increasing dithranol concentrations $(0$, $0.1,0.25$, and $0.5 \mu \mathrm{g} / \mathrm{mL}$ ) for $2 \mathrm{~h}$. A. Immunodetected protein band for procaspase-9, caspase-9 and GAPDH. B. Average fold over expression at $0 \mu \mathrm{g} / \mathrm{mL}$ dithranol for the procaspase-9 protein. C. Average fold over expression at $0 \mu \mathrm{g} / \mathrm{mL}$ dithranol for the caspase-9 protein. $* \mathrm{P}<0.05$ indicating a statistically significant difference.

\section{DISCUSSION}

Given the potential roles of E2A and caspase-9 as biomarkers in psoriasis, they were studied in the present investigation since we hypothesized that dithranol acted therapeutically by targeting E2A and caspase-9. Various studies have shown that E2A was extremely critical for cell proliferation and differentiation (Yan et al., 1997; Engel and Murre, 2001; Perk et al., 
2005; Kee, 2009). Although E2A binding partner, Id1, has been revealed to be important in psoriasis according to various reports (Bjorntorp et al., 2003; Mark et al., 2006; Ronpirin et al., 2010), the knowledge concerning the molecular involvement of E2A in psoriasis still remains limited. Apoptosis, another pathway undoubtedly imbalanced in psoriasis, is crucial in the maintenance of skin cell homeostasis as well as in the pathogenesis of certain skin diseases including psoriasis, but only few studies on caspase-9 in psoriasis have been reported to date (Yamamoto and Nishioka, 2003; Oztas et al., 2006).

In the quantitative real-time PCR approach, we employed the UBC gene as a housekeeping gene control, and total RNA was isolated from the HaCaT cells after $2 \mathrm{~h}$ of dithranol treatment for subsequent experiments. The statistical significance was reached when treating $\mathrm{HaCaT}$ cells with $0.5 \mu \mathrm{g} / \mathrm{mL}$ dithranol for E2A mRNA transcripts, while both 0.25 and 0.5 $\mu \mathrm{g} / \mathrm{mL}$ concentrations of dithranol resulted in a significant difference for caspase- 9 mRNA transcripts. However, as compared to $0 \mu \mathrm{g} / \mathrm{mL}$ dithranol concentrations, the significant levels of normalized E2A and caspase-9 mRNA transcripts were found to be increased by about 1.5and 1.2-fold, respectively. Therefore, slightly upregulated mRNA transcripts of both E2A and caspase- 9 were found in response to increasing concentrations of dithranol. It is worth noting that the real-time PCR results seem to support our hypothesis that i) dithranol lessens psoriatic activity by promoting E2A gene expression, thus increasing cell differentiation and decreasing cell proliferation, and ii) dithranol decreases psoriatic activity by enhancing caspase- 9 gene expression, thus increasing cell apoptosis. Nonetheless, the Western blot results seem to disagree since an insignificant change in the E2A protein and a tendency towards a decrease in the caspase- 9 protein were experimentally observed in this study. One might assume that decrease in the procaspase- 9 protein could be due to a result of cleavage of full-length caspase-9, thus resulting in more expression of its active form. However, we also found a decrease in its active form, therefore in line with the full-length form. Indeed, only certain caspases are fully processed in cells. For instance, nine caspases were found to be expressed in normal human epidermis, but only caspase-14 was fully processed (Raymond et al., 2007). Nevertheless, in our in vitro cellular model, the HaCaT cell line was clearly proven to express both procaspase- 9 and caspase-9. It is worth mentioning that the assay for caspase- 9 activity should also be carried out in order to give an insight into the molecular role of caspase-9 in response to dithranol. According to the previous in vivo study, dithranol therapeutically promoted apoptosis in psoriatic patients (Yamamoto and Nishioka, 2003). However, the in vitro effect of dithranol on apoptosis in the HaCaT cells was unlikely (Henseleit et al., 1996), thereby being consistent with our finding that caspase- 9 might not be a therapeutic target for dithranol.

It should be considered that inconsistent results were found between the two experimental approaches, real-time PCR and Western blot. This might be explained not only by the difference in sensitivity between the two techniques, but the difference in utilization of housekeeping genes as well. The latter seems to be considerably more logical in this case. Nevertheless, GAPDH and $\beta$-actin have been commonly used as reference genes for protein studies in various cell types including the $\mathrm{HaCaT}$ cells. Recently, proper reference genes for quantitative real-time PCR in human epidermal keratinocytes have been reported, and, in contrast to GAPDH and $\beta$-actin, UBC was one of the most stable genes (Allen et al., 2008). Therefore, UBC was chosen as an internal control for our real-time PCR analysis. It is noteworthy, that using more than one reference genes is better in order to assure data trustworthiness. Furthermore, we were not surprised by these contradictory results since the real-time PCR showed 
only slight upregulation of E2A and caspase-9 mRNA levels. In the near future, it would be better to study the gene expression profile since many biomarkers in the network profile are likely to provide a useful insight into a better understanding of signaling cascades involved.

\section{ACKNOWLEDGMENTS}

Research supported by the Royal Thai Government Research Fund 2009 (to C. Ronpirin) and the Chulalongkorn University Centenary Academic Development Project (to T. Tencomnao).

\section{REFERENCES}

Allen D, Winters E, Kenna PF, Humphries P, et al. (2008). Reference gene selection for real-time rtPCR in human epidermal keratinocytes. J. Dermatol. Sci. 49: 217-225.

Bjorntorp E, Parsa R, Thornemo M, Wennberg AM, et al. (2003). The helix-loop-helix transcription factor Id1 is highly expressed in psoriatic involved skin. Acta Derm. Venereol. 83: 403-409.

Boukamp P, Petrussevska RT, Breitkreutz D, Hornung J, et al. (1988). Normal keratinization in a spontaneously immortalized aneuploid human keratinocyte cell line. J. Cell Biol. 106: 761-771.

Bradford MM (1976). A rapid and sensitive method for the quantitation of microgram quantities of protein utilizing the principle of protein-dye binding. Anal. Biochem. 72: 248-254.

Engel I and Murre C (2001). The function of E- and Id proteins in lymphocyte development. Nat. Rev. Immunol. 1: 193199.

Farkas A, Kemeny L, Szony BJ, Bata-Csorgo Z, et al. (2001). Dithranol upregulates IL-10 receptors on the cultured human keratinocyte cell line HaCaT. Inflamm. Res. 50: 44-49.

Henseleit U, Rosenbach T and Kolde G (1996). Induction of apoptosis in human HaCaT keratinocytes. Arch. Dermatol. Res. 288: 676-683.

Kee BL (2009). E and ID proteins branch out. Nat. Rev. Immunol. 9: 175-184.

Kemeny L, Ruzicka T and Braun-Falco O (1990). Dithranol: a review of the mechanism of action in the treatment of psoriasis vulgaris. Skin Pharmacol. 3: 1-20.

Kuida K (2000). Caspase-9. Int. J. Biochem. Cell Biol. 32: 121-124.

Langlands K, Down GA and Kealey T (2000). Id proteins are dynamically expressed in normal epidermis and dysregulated in squamous cell carcinoma. Cancer Res. 60: 5929-5933.

Lowes MA, Bowcock AM and Krueger JG (2007). Pathogenesis and therapy of psoriasis. Nature 445: 866-873.

Mark EB, Jonsson M, Asp J, Wennberg AM, et al. (2006). Expression of genes involved in the regulation of p16 in psoriatic involved skin. Arch. Dermatol. Res. 297: 459-467.

Olson EN and Klein WH (1994). bHLH factors in muscle development: dead lines and commitments, what to leave in and what to leave out. Genes Dev. 8: 1-8.

Oztas P, Lortlar N, Oztas MO, Omeroglu S, et al. (2006). Caspase 9 is decreased in psoriatic epidermis. Acta Histochem. 108: 497-499.

Pavithran K (2001). Psoriasis: topical treatment. Indian J. Dermatol. Venereol. Leprol. 67: 85.

Perk J, Iavarone A and Benezra R (2005). Id family of helix-loop-helix proteins in cancer. Nat. Rev. Cancer 5: 603-614.

Raymond AA, Mechin MC, Nachat R, Toulza E, et al. (2007). Nine procaspases are expressed in normal human epidermis, but only caspase-14 is fully processed. Br. J. Dermatol. 156: 420-427.

Ronpirin C, Achariyakul M, Tencomnao T, Wongpiyabovorn J, et al. (2010). Up-regulation of Id1 in peripheral blood of psoriatic patients. Genet. Mol. Res. 9: 2239-2247.

Schon MP and Boehncke WH (2005). Psoriasis. N. Engl. J. Med. 352: 1899-1912.

Tencomnao T, Ronpirin C, Prasansuklab A and Poovorawan Y (2009). Decreased EGFR mRNA expression in response to antipsoriatic drug dithranol in vitro. Afr. J. Biotechnol. 8: 3141-3146.

Yamamoto T and Nishioka K (2003). Alteration of the expression of Bcl-2, Bcl-x, Bax, Fas, and Fas ligand in the involved skin of psoriasis vulgaris following topical anthralin therapy. Skin Pharmacol. Appl. Skin Physiol. 16: 50-58.

Yan W, Young AZ, Soares VC, Kelley R, et al. (1997). High incidence of T-cell tumors in E2A-null mice and E2A/Id1 double-knockout mice. Mol. Cell Biol. 17: 7317-7327. 